\title{
BACHARELADO INTERDISCIPLINAR EM SAÚDE DA UNIVERSIDADE FEDERAL DA BAHIA (UFBA): FATORES DE ESCOLHA DOS ESTUDANTES INGRESSOS
}

\author{
BACHARELADO INTERDISCIPLINAR EN SALUD DE LA \\ UNIVERSIDADE FEDERAL DA BAHIA (UFBA): FACTORES DE \\ ELECCIÓN DE LOS ESTUDIANTES INGRESOS
INTERDISCIPLINARY BACHELOR PROGRAM OF HEALTH OF UNIVERSIDADE FEDERAL DA BAHIA (UFBA): PREVAILING \\ FACTORS IN STUDENT'S CHOICE
}

\author{
Renata Meira Veras ${ }^{1}$ e Carolinne Montes Baptista ${ }^{1}$ \\ ${ }^{1}$ Universidade Federal da Bahia, Salvador/BA, Brasil
}

\begin{abstract}
RESUMO: Baseado no modelo de ciclos, os Bacharelados Interdisciplinares da UFBA se configuram pela formação interdisciplinar e não profissionalizante. Por ser o primeiro ciclo, os estudantes podem, após seu término, migrar para um Curso de Progressão Linear (CPL), para a pós-graduação ou para o mercado de trabalho. Esse artigo tem como objetivo identificar os fatores predominantes na escolha dos estudantes pelo Bacharelado Interdisciplinar em Saúde. Utilizando a pesquisa qualitativa, participaram da pesquisa 14 estudantes desse curso. Foram utilizadas entrevistas semiestruturadas e grupos focais. Os resultados, analisados a partir da análise de discurso, demonstram que os estudantes procuram o BI de saúde por almejar um CPL, especialmente Medicina, a partir da expectativa de ascensão econômica e social. No entanto, os relatos também indicaram que o caráter interdisciplinar do curso contribuiu para que a escolha pudesse ser feita pelos estudantes de forma mais elaborada e refletida.

PALAVRAS-CHAVE: Universidade; Bacharelado interdisciplinar em Saúde; Medicina.
\end{abstract}

RESUMEN: Basado en el modelo de ciclos, los Bachilleres Interdisciplinarios de la UFBA se configuran por la formación interdisciplinaria y no profesionalizante. Pro ser el primer ciclo, los estudiantes pueden, después de su término, migrar a un Curso de Progresión Lineal (CPL), ao postgrado o al Después de su conclusión, los estudiantes pueden acceder a un curso profesional, para el postgrado o para el mercado de trabajo. Este artículo tiene como objetivo identificar los factores predominantes en la elección de los estudiantes por el Bachillerato Interdisciplinario en Salud. Utilizando la investigación cualitativa, participaron de la investigación 14 estudiantes de ese curso. Se utilizaron entrevistas semiestructuradas y grupos focales. Los resultados, analizados a partir del análisis de discurso, demuestran que los estudiantes buscan el BI de salud por anhelar un CPL, especialmente Medicina, a partir de la expectativa de ascensión económica y social. Sin embargo, los relatos también indicaron que el carácter interdisciplinario del curso contribuyó para que la elección pudiera ser hecha por los estudiantes de forma más elaborada y reflejada.

PALABRAS CLAVE: universidad; bachillerato interdisciplinario en salud; medicina.

ABSTRACT: Based on the model of cycles, the Interdisciplinary Bachelors (BI) of the UFBA are configured by interdisciplinary and non-professional training. Because it is the first cycle, upon completion, students may choose to migrate to a Linear Progression Course (CPL), a postgraduate course or the job market. This article aims to identify the predominant factors that constitute the student's choice for the Interdisciplinary Bachelor in Health. Using the qualitative research, 14 students participated in this study. Semi-structured interviews and focus groups were used. The results, analyzed from the discourse analysis, show that the students seek the BI in Health because they aim for a CPL, especially in Medicine, driven by an expectation of economic and social ascension. However, the reports also indicated that the interdisciplinary nature of the course contributed to a more elaborate and considered choice of students. KEYWORDS: University; Interdisciplinary Bachelor in Health; Medicine. 


\section{Introdução}

O Plano Nacional de Educação (Lei n.10.172, 2001) teve como objetivo prover a oferta de educação superior até o final da década para 30\% da população entre 18 e 24 anos. No entanto, os dados do Instituto Nacional de Estudos e Pesquisas Educacionais Anísio Teixeira (INEP) indicam que apesar do alto número de matrícula na educação superior em 2014 (7.828.013), a evasão do ensino superior, que foi de 11,4\% em 2010, chegou a 49\% em 2014.

Para Silva, Montejunas, Hipólito e Lobo (2007) o índice de evasão é duas a três vezes maior no primeiro ano do curso do que nos anos seguintes. Portanto, a escolha vocacional/profissional é uma questão fundamental no momento da entrada na universidade, quando o jovem tem de optar por um curso e começar a definir qual carreira almeja construir. Segundo Macedo (1998), a temática da carreira profissional tem sido amplamente abordada nos últimos anos, pois novos cargos e novas oportunidades de trabalho começam a surgir em um ritmo bastante acelerado, acompanhados das questões da globalização e dos avanços tecnológicos.

Nesse sentido, reconhece-se que o trabalho é um dos espaços mais importantes de subjetivação e definição de identidades no mundo dos adultos, ainda que, paradoxalmente, na sociedade capitalista, o trabalho esteja normalmente condicionado pela necessidade extrínseca e raramente se constitui como uma forma de realização pessoal. Num mundo perpassado por iniquidades socioeconômicas e relações de poder, as materialidades do contexto da atividade produtiva definem, de fato, o grau de controle que o trabalhador tem sobre o que produz (Traverso-Yepez, 2008).

Consequentemente, reconhece-se que as novas demandas no mundo do trabalho tendem a exigir mudanças na formação desses profissionais. Assim, na tentativa de contribuir com o processo de mudança no panorama da educação superior brasileira, surgiu, em 2007, na Universidade Federal da Bahia (UFBA), a proposta da Universidade Nova. Esta proposta apresentou-se como uma mudança na arquitetura curricular dos cursos, que juntamente com o Programa de Apoio a Planos de Reestruturação e Expansão das Universidades Federais Brasileiras (REUNI) do governo federal, oportunizou o surgimento dos Bacharelados Interdisciplinares da UFBA. Esta iniciativa emergiu influenciada pelo esgotamento do modelo de graduação profissionalizante e seus principais impactos, como, por exemplo, o alto índice de evasão universitário e defasagem das metodologias e estratégias pedagógicas (Veras, Lemos, \& Macedo, 2015).

Baseado no modelo de ciclos, esses cursos interdisciplinares correspondem ao primeiro ciclo e abrangem grandes áreas do conhecimento, trabalhando com as três culturas como eixos estruturantes do saber: a cultura humanística, a cultura artística e a cultura científica (Almeida-Filho, 2007). Assim, os Bacharelados Interdisciplinares (BI) são ofertados em quatro grandes áreas: saúde, humanidades, artes e ciências e tecnologia.

Além da reestruturação do modelo de ensino, os BI propõem promover uma democratização maior do acesso à universidade, ou seja, permitir que classes populares tenham mais uma possibilidade de frequentar o ensino superior. Devido à sua natureza de ciclo, existe, portanto, a possibilidade de o estudante esperar mais tempo para amadurecer a escolha profissional enquanto cursa disciplinas de vários cursos (Pimentel, Rubim, Bastos, Embiruçu, Marinho, Nery et al., 2008).

A relevância dos processos de significação e geração de sentido na experiência de escolha profissional é cada vez mais reconhecida. Uma psicologia social aplicada ao campo do trabalho considera como objeto de estudo o universo simbólico que perpassa desde a escolha do curso, a 
experiência dos profissionais e demais atores sociais nos sistemas institucionais de cuidado da saúde, até a sociedade como um todo. As expressões de subjetividade, cultura, encontro, interação e relações dialógicas são termos comuns na Psicologia Social. Igualmente, esses termos tendem a estar cada vez mais presentes nos textos de formação profissional, almejando mudanças nas formas tradicionais do fazer desses atores sociais (Traverso-Yépez, 2008).

Nesse sentido, este estudo tem o intuito de compreender se os estudantes, ao ingressar no BI Saúde, tinham conhecimento da proposta mais ampla do BI, se buscavam uma definição vocacional e quais fatores predominaram na opção por esse curso. Portanto, tem como objetivo analisar os fatores predominantes na escolha dos estudantes ingressos para o Bacharelado Interdisciplinar em Saúde da UFBA.

\section{Escolha vocacional/profissional e a entrada na universidade}

Pode-se definir a escolha profissional como o estabelecimento do que fazer, de quem ser e a que lugar pertencer no mundo por meio do trabalho. É importante esclarecer que a escolha profissional não é uma decisão isolada, mas um processo contínuo, que abrange uma série de decisões tomadas ao longo de vários anos da vida. Tal processo se aguça na juventude, quando uma decisão quanto à futura profissão ou ocupação deve ser tomada (Neiva, 2007).

No entanto, ao escolher uma profissão, os jovens brasileiros têm pouca ou nenhuma informação concreta como base. As escolas brasileiras estão planejadas e estruturadas de tal forma que não contribuem no processo de decisão, já que há uma tendência em massificar o corpo discente, anulando a individualidade do aluno, onde não há uma adaptação do conteúdo das aulas à realidade do mundo do trabalho (Moreira, 2000).

Para o mesmo autor, o jovem hoje está cada vez mais preocupado em "como sobreviver", o que fazer para "ganhar dinheiro" e obter status, sem atentar para as suas aptidões e preferências. Os pais também acabam priorizando as profissões de status, influenciando fortemente a escolha profissional dos filhos, dando pouca importância à satisfação e realização do jovem e muita importância ao diploma.

Alguns fatores ligados à autonomia do jovem, que interferem na escolha vocacional/profissional, são seus próprios interesses pessoais, preferências, gostos por uma ou outra área do conhecimento ou profissão (Almeida \& Pinho, 2008; Faria, 2013; Luna, 2012; Magalhães, Straliotto, Keller, \& Gomes, 2001; Natividade \& Brasil, 2006). Muitas vezes, o interesse por determinada profissão surge do envolvimento ou experimentação de atividades ligadas à área desejada (Louzada \& Silva, 2008; Ribeiro, Leal, Diamantino, \& Bianchi, 2011). Outros fatores são a vontade, o esforço e o mérito pessoal. Porém, alguns autores salientam que há que se cuidar ao avaliá-los, pois, às vezes, o indivíduo não acessa as condições adequadas para poder expressá-los, como é o caso da baixa qualidade no ensino básico e médio, bem como limitações socioeconômicas (Gabel \& Soares, 2006; Melsert \& Bicalho, 2012).

Sobre o abandono dos estudos no ensino superior, Kipnis (2000) coloca que para o estudante que abandona uma instituição de nível superior, "a questão da evasão deve ser referenciada aos seus objetivos de entrada. Portanto, segundo o ponto de vista do aluno, a evasão significa o fracasso em atingir os seus objetivos desejados ao entrar na instituição." (Kipnis, 2000, p. 114). Já a partir da visão da instituição, Kipnis conclui que a "definição torna-se melhor observável quando o estudante deixa a instituição”, sem ter obtido o diploma. Nessa perspectiva, ele também observa que é importante diferenciar os casos de abandono daque- 
les ocorridos pelo funcionamento da instituição. Já para os gestores da educação superior no plano nacional, evasão é "só se o indivíduo deixou completamente o sistema de ensino" (Kipnis, 2000, p. 115).

Sobre os dados de evasão na UFBA, o índice em 2011 foi de 47\% (IHAC, 2017). Já nos cursos de Bacharelado Interdisciplinar, 38,3\% dos alunos tem abandonado a graduação, sendo 38,9\% do BI em Artes, 31,3\% do BI em Ciência e Tecnologia, 38,8\% do BI em Humanidades e 42\% no BI em Saúde (Andrade, 2014).

Um estudo realizado na UFBA, em 2012, trouxe dados relativos aos índices de diplomação, retenção e evasão na instituição no período de 1993 a 2010. Na pesquisa, foram incluídos 53 cursos instalados até 2006, antes do REUNI, e os resultados mostraram que o curso de Engenharia de Minas apresentou o maior índice de evasão (83,9\%), e o curso de Medicina obteve menor índice (7,1\%) (Andrade, 2014).

As taxas de evasão e as dificuldades na escolha profissional se agravam quando se trata de jovem de origem popular, pois o acesso e a permanência no ensino superior são mais difíceis, devido às desigualdades socioeducacionais (Teixeira, 2011).

Os indicadores sociais do Instituto Brasileiro de Geografia e Estatística (IBGE, 2012) mostram que os jovens entre 18 e 24 anos mais pobres da população brasileira possuem, em média, 7,7 anos de estudo, enquanto que os mais ricos possuem 11,7 anos. Dos jovens matriculados nas universidades públicas, apenas $7,1 \%$ estão entre os $20 \%$ mais pobres da população, sendo que $41 \%$ estão entre os $20 \%$ mais ricos.

No entanto, Bastos (2005) afirma que, nas últimas décadas, houve um aumento da oferta de ensino médio público no Brasil, o que tem permitido o acesso de milhares de jovens de origem popular ao ensino superior, que até então não tinham a oportunidade de cursá-lo. Esse fato também aumenta as chances desses jovens ingressarem no mercado de trabalho em profissões que exigem maior qualificação e facilita o processo de escolha profissional, apesar de que a efetivação da escolha vai depender de uma série de fatores. A falta de recursos financeiros para pagar um cursinho pré-vestibular ou uma faculdade, a necessidade de trabalhar em paralelo aos estudos e a impossibilidade de concorrer com igualdade com alunos oriundos de classes economicamente favorecidas podem ter um peso decisivo na concretização de suas escolhas. Muitos desses jovens não escolhem sua ocupação ou profissão, pois é possível apenas escolher a carreira que está mais acessível. O que acaba por determinar sua escolha profissional são fatores de natureza econômica e social, tais como o mercado de trabalho, importância social, remuneração, tipo de trabalho (braçal/intelectual) e as habilidades necessárias para o seu desempenho, que lhe darão as condições básicas de escolaridade, não existindo espaço para determinantes vocacionais (Bock, Furtado, \& Teixeira, 2001).

\section{Bacharelado interdisciplinar em saúde da UFBA}

O Bacharelado Interdisciplinar [BI] é um curso de graduação universitária interdisciplinar, com terminalidade própria, que habilita o estudante após as 2.400 horas de curso, com o título de Bacharel em sua Área (saúde, artes, humanidades e ciências) a atuar no setor público, no segmento empresarial e no campo não-governamental associativo, podendo também servir como requisito para a formação profissional de graduação (em outros cursos da própria universidade) ou ingressar num programa de pós-graduação (Almeida-Filho, 2010). 
Com base nessa proposta inovadora, o Bacharelado Interdisciplinar em Saúde contempla a organização de um conjunto de eixos ou módulos que agregam diversos componentes curriculares, cujos conteúdos programáticos foram planejados para que os estudantes adquiram competências cognitivas e habilidades específicas que lhes permitam compreender a complexidade do campo da saúde na contemporaneidade (Teixeira, Coelho, \& Rocha, 2014), conforme se observa no quadro 1.

Quadro 1 - Síntese da distribuição dos componentes curriculares do BIS

\begin{tabular}{|c|c|c|}
\hline Eixo ou módulos & Componente curricular & $\begin{array}{l}\text { Carga } \\
\text { Horária }\end{array}$ \\
\hline $\begin{array}{l}\text { Módulo } \\
\text { interdisciplinar }\end{array}$ & $\begin{array}{l}\text { HACA01- Estudos sobre a Contemporaneidade I } \\
\text { HACA34-Estudos sobre a Contemporaneidade II }\end{array}$ & $\begin{array}{l}68 \mathrm{~h} \\
68 \mathrm{~h}\end{array}$ \\
\hline Módulo Culturas & $\begin{array}{l}2 \text { CC Cultura humanística (a escolher) } \\
2 \text { CC Cultura artística (a escolher) }\end{array}$ & $\begin{array}{l}136 \mathrm{~h} \\
136 \mathrm{~h}\end{array}$ \\
\hline Eixo Linguagens & $\begin{array}{c}\text { LETE43 - Língua portuguesa, poder e diversidade } \\
\text { LETE45 - Leitura e Produção de textos em } \\
\text { Língua Portuguesa } \\
\text { HACA78 - Oficina de textos acadêmicos e } \\
\text { técnicos em saúde }\end{array}$ & $\begin{array}{l}68 \mathrm{~h} \\
68 \mathrm{~h} \\
68 \mathrm{~h}\end{array}$ \\
\hline $\begin{array}{c}\text { Formação } \\
\text { específica } \\
\left(1^{\text {a }} \text { etapa }\right) \\
\text { CC obrigatórios }\end{array}$ & $\begin{array}{l}\text { HACA } 10 \text { - Introdução ao Campo da saúde } \\
\text { HACA40 - Campo da Saúde: saberes e práticas } \\
\text { HACB17 - Saúde, Educação e Trabalho }\end{array}$ & $\begin{array}{l}68 \mathrm{~h} \\
68 \mathrm{~h} \\
68 \mathrm{~h}\end{array}$ \\
\hline $\begin{array}{c}\text { Formação especí- } \\
\text { fica } \\
\left(2^{\text {a }} \text { etapa }\right) \\
\text { CC optativos }\end{array}$ & $\begin{array}{c}11 \text { componentes curriculares oferecidos pelas } \\
\text { unidades de saúde e/ou pelo Instituto de } \\
\text { Humanidades, Artes e Ciências }\end{array}$ & $748 \mathrm{~h}$ \\
\hline TOTAL & & $1020 \mathrm{~h}$ \\
\hline $\begin{array}{l}\text { Atividades } \\
\text { Complementares }\end{array}$ & & $360 h$ \\
\hline Componentes livres & (7 componentes livres de 68 horas) & $476 \mathrm{~h}$ \\
\hline TOTAL GERAL & & 240oh \\
\hline
\end{tabular}

Fonte: IHAC, 2017

O eixo interdisciplinar é composto por dois módulos: o módulo interdisciplinar, formado pelos Componentes Curriculares (CC) Estudos da Contemporaneidade I e II, que, segundo o projeto pedagógico do BI de saúde, fornece ao estudante uma compreensão interdisciplinar dos processos sociais, e o módulo das culturas, que o estudante escolherá quais serão as culturas artísticas e humanísticas que irão cursar, baseado nos seus interesses de aprendizagem. Essas 
disciplinas são ofertadas pelo próprio IHAC e por outras unidades acadêmicas da UFBA. Esse modelo possibilita ao estudante conhecer diversos cursos de formação superior, estabelecendo várias redes de relacionamento e colaboração dentro do multicampi da universidade.

O eixo das linguagens é formado por dois módulos: o de língua portuguesa e o de língua estrangeira. O primeiro deles é formado pelos componentes: LET E43 - Língua Portuguesa, Poder e Diversidade, LET E45 - Língua e Produção de Textos em Língua Portuguesa e HAC A78 - Oficina de Textos Acadêmicos e Técnicos em Saúde.

O segundo módulo é o de língua estrangeira, no qual o projeto pedagógico do curso reforça a importância do domínio instrumental de outro idioma além da língua materna, para ampliar a aquisição de outros conhecimentos.

A formação específica em saúde acontece em duas etapas. Na $1^{\text {a }}$ etapa da formação específica, o estudante possui três componentes curriculares que irão tratar sobre o campo da saúde. Já na segunda etapa, o estudante poderá se inserir em alguma área de concentração ou cursar $11 \mathrm{CC}$ de sua escolha na área da saúde. É nesse momento que o estudante poderá transitar e articular os conhecimentos já aprendidos sobre a saúde e agregar outros nas diversas graduações da área que a universidade possui, além de poder cursar componentes curriculares comuns a todos os cursos de saúde, tais como: anatomia, fisiologia, biofísica e etc. Essa etapa confere ao estudante o seu caráter de profissional da saúde.

Além disso, os estudantes deverão cumprir 7CC livres, ou seja, cursarão componentes de livre escolha pela universidade sem se prender a uma área do conhecimento especifica, além das 360h de carga horária complementar (eixo integrador), podendo cumpri-las através de monitorias, iniciação cientifica, projetos de extensão, cursos e eventos acadêmicos. Concluídas as 2400h, o estudante recebe o título de Bacharel em Saúde.

Ressalta-se que os Bacharelados Interdisciplinares da UFBA constituem uma proposta nova de graduação, na qual o aluno pode ingressar no ensino superior e ter um tempo maior para definir a sua escolha vocacional/profissional, podendo construí-la ao longo do curso, pois não se trata de um curso de progressão linear (CPL) ou profissionalizante, a exemplo os cursos de Direito, Medicina, Psicologia, Administração, Engenharia, dentre outros, mas de um curso de formação geral e interdisciplinar, que permite o contato com várias áreas do conhecimento, tais como: humanidades, artes, saúde, ciência e tecnologia, antes da realização de uma escolha vocacional/profissional.

De acordo com o IHAC (2017), os CPL que tiveram maior procura por parte dos estudantes do BI Saúde entre 2012 e 2017 estão apresentados no quadro 2:

Quadro 2: Número de estudantes ingressantes nos Cursos de Progressão Linear

\begin{tabular}{|c|c|}
\hline Curso de Progressão Linear & Número de estudantes ingressantes \\
\hline Medicina & 217 \\
\hline Odontologia & 95 \\
\hline Enfermagem & 48 \\
\hline Saúde Coletiva & 30 \\
\hline Gastronomia & 30 \\
\hline
\end{tabular}

Fonte: IHAC, 2017 
O estudante do BI também pode optar em não seguir um curso de CPL e ingressar diretamente em uma formação de pós-graduação ou se lançar no mercado de trabalho em cargos que não exijam formação em área específica. No entanto, embora tenha um tempo maior para definir uma profissão e possa trilhar diversos caminhos na busca de sua vocação, o ingressante nos BI, ao optar em fazê-lo, sofre influências e motivações vindas dos pais, pares, mídia, dentre outros, tanto quanto o ingresso em um curso de CPL, só que estas podem apresentar nuances diferentes.

\section{Método}

A estratégia metodológica escolhida para essa pesquisa foi a qualitativa. Para Minayo (2008), essa perspectiva, além de possuir uma característica descritiva, se aplica ao estudo da história, das relações, das representações, das crenças, das percepções que os humanos fazem a respeito de como vivem, constroem seus artefatos e a si mesmos, sentem e pensam.

Para coleta de dados, os instrumentos utilizados foram entrevistas semiestruturadas e grupos focais. As entrevistas em profundidade foram realizadas com 7 estudantes recém ingressados nos Bacharelado Interdisciplinar em Saúde da UFBA, em 2014.1. Esses estudantes foram abordados no momento da sua matrícula no BI, em março de 2014. Após a aceitação do convite, foi entregue aos entrevistados o Termo de Consentimento Livre e Esclarecido (TCLE), para que tivessem o conhecimento de que se tratava a pesquisa, bem como sobre as suas implicações éticas, de acordo com a Resolução de Pesquisa com seres humanos (Resolução 196). As entrevistas foram realizadas entre 10 e 14 de março de 2014 com duração entre 23 e 42 minutos.

Também foram realizados 3 grupos focais no mês de março de 2014, contendo estudantes das várias modalidades de BI e de variados semestres, ou seja, grupos heterogêneos, sendo 2 grupos com 4 participantes e 1 grupo com 9. O total de participantes do BI Saúde nos grupos focais foram 7 estudantes. Portanto, o número total de estudantes envolvidos na pesquisa foram 14. As questões norteadoras para entrevistas e grupos focais foram: os motivos para escolha pelo BI e as perspectivas futuras com o término do curso.

Os critérios para participação da pesquisa foram: alunos regularmente matriculados em um Bacharelado Interdisciplinar e que estivessem cursando os três primeiros semestres, período em que o aluno cursa todos os componentes curriculares obrigatórios do Instituto de Humanidades, Artes e Ciências, instituto que abriga os Bacharelados Interdisciplinares na UFBA.

Após a coleta realizada nas entrevistas em profundidade e nos grupos focais, os dados foram transcritos e submetidos à análise de discurso. A análise de discurso trabalha com o sentido e não com o conteúdo do texto, um sentido que não é traduzido, mas produzido pelo coletivo, o qual o sujeito é apenas um porta voz do discurso e representante daquele sentido (Phillips \& Hardy, 2002).

A análise do discurso de Willig (2010) e Phillips e Hardy (2002) são abordagens que consideram o cotidiano como "discursivamente organizado", enfatizando o papel da linguagem na organização das ideias, representações e do universo simbólico presente nas relações interpessoais e institucionais. Essa forma de análise permite também verificar como o poder é reproduzido e legitimado pela fala e pelos textos dos grupos dominantes ou instituições (Veras, 2011). 
Para a discussão dos dados, os entrevistados foram identificados com nomes de flores, para preservar o sigilo sobre sua identidade. O estudo teve aprovação do Comitê de Ética do da Escola de Enfermagem da UFBA, aprovado em setembro de 2014, no do parecer 778094 CEP/UFBA.

\section{Resultados e discussão}

A análise dos relatos permitiu desvelar os motivos que levaram os estudantes pesquisados a escolher o curso do Bacharelado Interdisciplinar em Saúde da UFBA, uma modalidade recente de graduação, com características interdisciplinares e de formação geral.

Observou-se nos relatos das entrevistas que os motivos alegados para a escolha desse curso foi a possibilidade de ingressar em um Curso de Progressão Linear (CPL) após a sua conclusão. Há um destaque com relação à opção pelo curso de Medicina, os quais declararam ter escolhido fazer BI como uma alternativa para ingressar nesse curso, como mostram as falas:

Eu passei três anos no curso pré-vestibular, prestei vestibular para três áreas, humanística, exatas e biológicas, mas o que eu vi que eu tinha mesmo afinidade era com a parte biológica, então eu escolhi Medicina, como eu não passei, acabei entrando no BI, como uma alternativa para entrar em Medicina. (Cravo)

Eu sempre quis, tive o sonho de fazer Medicina, fiz um curso preparatório durante dois anos. Quando saí do ensino médio, e aí, eu não conhecia o BI, meus amigos falaram que tinha a oportunidade de cursar Medicina pelo BI, aí fui ver o SISU, minha nota entrava e aí eu acabar entrando. (Antúrio)

Quando eu entrei no BI, quando botei lá no ENEM, BI de saúde, eu queria porque me falaram que eu tinha como fazer Medicina, pelo BI de Saúde. (Lírio)

Escolhi com o intuito de migrar para Medicina após o término do curso. (Cravina)

Fica claro nessas falas que os estudantes viram no BI um caminho para contornar as dificuldades de ingresso em Medicina, curso altamente concorrido e que exige notas altas no Enem. O status das profissões é considerado um fator bastante relevante na escolha dos jovens por uma carreira profissional. Principalmente naqueles que aspiram carreiras como Medicina (Ribeiro, Leal, Diamantino, \& Bianchi, 2011) e os cursos mais valorizados historicamente (Almeida \& Pinho, 2008; Costa, 2007; Dias \& Soares, 2012; Torres, 1998).

Assim, mesmo os que alegaram indecisão quanto à escolha, a medicina estava presente como um dos cursos almejados, como mostram os relatos:

Na verdade, é, eu tive indecisão, eu fiquei entre medicina e biofísica, e aí eu tinha passado em Biofísica, só que não é aqui em Salvador e aí eu preferi pelo BI mesmo, foi mais pela indecisão mesmo e também porque minha nota não dava pra medicina, aí eu falei, não BI que é um caminho a mais, que eu possa estar percorrendo. (Celósia)

Escolhi o BI mais por uma indecisão, de não saber realmente o que eu quero ser como profissional. Eu fiz vestibular para Biologia, pra medicina, pra biotecnologia, então eu 
tava com muita dúvida em relação a qual CPL eu, e, mas eu sabia a minha área, eu sabia que era área da saúde, mas ainda não sei qual CPL quero. (Hortência)

Depoimentos escritos por alunos dos BI, ao longo dos dois semestres do componente curricular Estudos da Contemporaneidade I e II, em 2009, mostraram que a opção pelos BI muitas vezes é uma forma de driblar as dificuldades impostas pela acirrada concorrência do vestibular, exame ainda vigente nesse período (Mazoni, Custódio, \& Sampaio, 2011).

Destaca-se que, em 2010, o vestibular foi substituído pelo Enem (Mazoni, Custódio, \& Sampaio, 2011 ), e em 2014 a UFBA toda aderiu ao Sisu, o que permite que a nota obtida no Enem seja utilizada para ingressar em qualquer curso, não só na UFBA, mas em qualquer universidade pública que tenha aderido ao Sisu. O candidato, ao efetuar sua inscrição nesse sistema, deve escolher, por ordem de preferência, até duas opções entre as vagas ofertadas pelas instituições que aderiram a ele. Normalmente os estudantes têm escolhido os cursos de CPL como primeira opção e os bacharelados interdisciplinares na UFBA como segunda opção, como uma chance a mais de ingressar na universidade e chegar até o curso almejado, como foi perceptível nas falas dos estudantes.

Mas e agora com o Sisu? Os estudantes continuam vendo no BI uma alternativa para driblar a concorrência na entrada em cursos socialmente privilegiados, como é o caso de medicina? E se o veem assim, haveria algum diferencial acessando esse curso a partir do modelo de ciclos?

Os estudantes Ciclame e Centáurea deixam bem claro o interesse pela medicina pelos fatores econômicos:

Eu usei sim o BI como um trampolim para medicina, quando eu entrei eu pensei em medicina pelo fato do retorno financeiro que o curso poderia me proporcionar, não pelo ah eu tenho amor...não! Não por amor, mas pelo retorno financeiro que eu poderia ter com o curso. Não tenho aptidão, não tenho nada... eu só gosto da área de saúde, eu gosto de estudar saúde coletiva, por exemplo. (Ciclame)

Eu entrei pensando no BI de Saúde, pensando em fazer medicina... eu já entrei com esse pensamento: vou fazer BI de Saúde, pra entrar em medicina e ganhar dinheiro, e depois eu faço Jornalismo se eu quiser. (Centáurea)

O poder aquisitivo que a profissão propiciará é considerado um fator importante na escolha dos adolescentes (Pereira \& Garcia, 2007). Também se destaca que para os jovens menos favorecidos economicamente, o diploma retém seu valor histórico e social simbólico, tendo um sentido múltiplo como condição de status social, de mobilidade e de melhores possibilidades de futuro e de carreira (Dias \& Soares, 2012).

Afinal, como colocam Almeida-Filho et al. (2010), o acesso à universidade costuma ser visto como um fator fundamental para a redução das desigualdades de renda e melhoria na qualidade de vida em sentido amplo. Segundo o autor, o padrão de seleção instituído até então, o vestibular, privilegiava candidatos com maior capital econômico e cultural, que ocupavam cursos de maior prestígio social e que formavam uma elite econômica e culturalmente privilegiada. No entanto, essa realidade tem mudado. Os dados do Instituto Nacional de Estudos e Pesquisas Educacionais Anísio Teixeira (Inep), a partir de pesquisa realizada em 2011, mostram que, nos jovens de 18 a 24 anos, evolui quase 10 vezes a presença dos $20 \%$ de menor renda na universidade: de 0,5\%, em 1997, para 4,2\%, em 2011 , 
enquanto que os $20 \%$ de maior rendimento cresceram em menor ritmo: de 22,9\% para $47,1 \%$, pouco mais que o dobro (Sampaio, Barbosa, Santos, Fernandes, \& Dantas, 2013).

Sobre a passagem do BI Saúde para os cursos de CPL, dos 569 estudantes que fizeram migração entre 2012 e 2017, 217 entraram no curso de Medicina, ou seja, 38\% deles (IHAC, 2017).

Por outro lado, a estudante Begônia disse que optou pelo BI Saúde para ter um tempo de preparar a família para dizer que o seu desejo não é fazer Medicina:

Eu entrei no BI de saúde, na verdade, porque minha família toda achava que eu ia fazer Medicina, por causa da minha família de médicos, e eu sempre quis fazer Veterinária, ai eu fiz o BI pra poder dar um tempo, pra amaciar a galera e avisar que eu não vou ser médica. Ai eu entrei no BI de saúde. (Begónia)

Reconhece-se na bibliografia a influência dos pais no processo de construção da autonomia, no prazer pelo estudo e no sucesso na área escolhida. Além disso, oferecem oportunidades e experiências, colaboram com a escola, propiciam sentimentos de aprovação (Carvalho, 2009).

A participação dos pais no desenvolvimento de carreira dos filhos se inicia na infância e permanece até a conclusão da graduação. Além disso, existem três níveis de influência: diálogo, apoio emocional e material, e influência pelo exemplo (Oliveira \& Dias, 2013).

Melsert e Bicalho (2012) defendem que o nível educacional dos pais interfere na escolha profissional dos filhos. Para esses autores, os pais que tem até o ensino médio tendem a ter filhos que se interessaram por áreas que caracterizam profissões reconhecidamente tradicionais, como Engenharia, Medicina e Jornalismo. Esses dados corroboram com os achados desse estudo:

Na minha família poucas pessoas ingressaram na universidade, e eu agora estou tendo a oportunidade de estar aqui, conseguindo almejar novos conhecimentos, adquirir novas conquistas. (Cravo)

Por outro lado, ressalta-se que na medida em que os indivíduos constroem sua identidade pessoal, constroem também sua identidade ocupacional, processo que envolve aspectos inconscientes e conscientes, bem como forças motivacionais, regras e valores pessoais (Melsert \& Bicalho, 2012; Oliveira \& Neiva, 2013; Pereira \& Garcia, 2007; Santos, 2010; Torres, 1998).

Portanto, a escolha vocacional/profissional é uma produção que reúne representações simbólicas, conjugadas às produções imaginárias, fantasiosas e ainda permeadas pelo real (Torres, 1998). Ela é muitas vezes movida por fantasias, sonhos da infância, chamados de motivação precoce, nos quais estariam envolvidos elementos inconscientes (Natividade \& Brasil, 2006; Ribeiro, Leal, Diamantino, \& Bianchi, 2011). De acordo com esses autores, a escolha do jovem é influenciada por aspectos do seu inconsciente, por suas experiências infantis, que delinearam suas motivações atuais, as quais ele próprio, enquanto ser no presente, pouco tem autonomia de escolha, sendo refém de seu passado e do que ficou armazenado em sua mente inconsciente, uma escolha, segundo Ribeiro, Leal, Diamantino, e Bianchi (2011) e Torres (1998), que vem desprovida da própria vontade e desejo consciente do indivíduo. 
Isso aparece claro no relato da estudante Hortência:

Acho que é aptidão, vontade de fazer algo, de estar presente, eu mesmo, eu penso em Medicina e quando eu vejo sei lá, eu vejo o médico sem fronteiras, eu vejo, sei lá, pessoas indo cuidar de crianças, de idosos, sabe só, simplesmente pelo fato de estar cuidando, de estar ajudando, isso me faz pensar em Medicina, eu acho que vocação pode ser isso, isso de querer fazer algo por aquilo. (Hor tência)

Uma pesquisa realizada no município de Caxias do Sul, no Rio Grande do Sul, com 655 estudantes de 23 diferentes cursos de graduação e instituições de ensino superior (IES) do primeiro ano, investigou em uma de suas questões a realização pessoal, aptidão e vocação para determinado curso ou profissão. Essa questão foi a que recebeu a melhor média de respostas (379 estudantes), os quais consideraram esses fatores muito importantes para a sua decisão por um curso superior ou profissão (Lucchiari \& Bonneaud, 1995).

Por outro lado, alguns relatos indicam que o Bacharelado Interdisciplinar em Saúde proporcionou a oportunidade de refletir acerca da escolha pelo curso profissionalizante já realizada previamente. Esse ponto é bem interessante, e destacou-se na pesquisa, pois os estudantes relataram que passaram por dúvidas quanto à profissão que iria seguir no futuro, e que o BI o faria ter mais segurança ou ajudou a vislumbrar outras possibilidades:

Entrei no BI com o intuito de fazer Medicina, mas agora vejo no BI uma oportunidade diferenciada... eu pude conhecer várias áreas... A gente fica meio assim, porque eu já não tenho mais certeza, conviç̧ão de que realmente é a área, assim continuo com desejo de fazer o curso que desejei inicialmente, mas já não é uma certeza, porque o BI já me possibilitou ter incerteza quanto a isso... várias opções pra escolher e questões que a gente pode passear, a gente pode conhecer e diferenciar nos conhecendo, um autoconhecimento. (Allium)

A princípio eu não tinha, eu tinha a ideia de pesquisar... mas depois eu optei por Medicina. Eu sabia que eu queria fazer pesquisa na área de saúde, mas não tinha um curso certo pra isso, eu só decidi depois que estava no BI. (Margarida)

Também foi apontado que a amplitude e a variedade de conteúdos que o Bacharelado Interdisciplinar oferece nas diferentes áreas do conhecimento, a interdisciplinaridade, enriquece a formação e permite realizar uma escolha vocacional/profissional mais segura e efetiva.

Teve uma coisa que me encantou no BI foi a possibilidade de eu conseguir, mesmo 'tando' no BI de saúde, eu conseguir fazer algumas disciplinas de CËT, ou pegar alguma de humanidades, que são coisas que eu gosto também além da área de saúde, eu gosto muito de matemática, então essa possibilidade de também estar em uma área que eu gosto e de também pegar um pouco de outras coisas que também me interessam mais, de poder ser interdisciplinar, mas abrangente. (Hortência)

Reconhece-se que os novos problemas colocados pela globalização e pelas profundas mudanças tecnológicas, com as consequentes implicações nas formas como e onde as pessoas trabalham e têm acesso a oportunidades formativas e profissionais, a interdisciplinaridade na teorização e na prática dos problemas vocacionais, tem interferido significativa- 
mente na escolha vocacional/profissional (Louzada \& Silva, 2008). Isso foi representado nas falas dos estudantes:

Indiretamente o BI ajuda 'pro' mercado de trabalho. Ele ajuda na formação, tanto de vida pessoal, quanto de vida profissional, não está centralizado só numa coisa né, como se fosse num cabresto, abre um leque... em vários sentidos, aí a ideia principal é essa. (Margarida)

Eu considero o BI fantástico, pois você pode conhecer um pouco de certos aspectos científicos, como eu já falei, artísticos, humanos, entre outros, 'pra' você poder seguir na sua graduação ou não. Permanecer no BI, fazer um concurso, ou seguir... eu acho que só precisa de mais apoio aos estudantes do BI. (Lírio)

Assim, percebe-se que a escolha vocacional/profissional não se trata apenas da identificação de características pessoais, de perfis, de âncoras de carreira, paixões e espíritos. Além desses aspectos idiossincráticos, precisa ser compreendido diferentes perspectivas, incluindo-se as macrossociais (Luna, 2012). Portanto, conhecer o contex to contemporâneo é importante para identificar essas perspectivas. A contemporaneidade permite ao indivíduo a liberdade de escolha e a elaboração de um projeto de vida reflexivo, constantemente repensado, de acordo com as transformações e necessidades que possam surgir. Sendo assim, ele se desenvolve em um contex to mais amplo e sofre influência das diversas esferas nele presentes: o meio social, a família e fatores como classe, geração, sexo, dentre outros, possuem papel fundamental nesse processo. Portanto, existe um paradoxo na construção de projetos de vida na sociedade contemporânea, sob a influência familiar e social (Almeida \& Magalhães, 2011).

\section{Considerações finais}

Os resultados desse estudo trazem importantes desafios para essa recente modalidade de graduação e para a UFBA. Ressalta-se, inicialmente, que a proposta de implantação do BI gerou ampla resistência de segmentos políticos da instituição, o que resultou na oferta de dois modelos curriculares na universidade: o tradicional, de ingresso direto em cursos de progressão linear (os profissionalizações), e o de ciclos, a partir do ingresso pelos BI.

Mesmo assim, a criação do Bacharelado Interdisciplinar em Saúde vem se configurando como um espaço profícuo de mudanças na área de saúde, pois permite que o estudante tenha a possibilidade de escolher conscientemente o caminho que irá seguir e obter uma formação mais ampla e diferenciada em saúde. Observa-se que os BI permitem trazer a escolha vocacional/profissional para dentro da universidade, possibilitam rever escolhas iniciais e mudar os rumos idealizados. Pode se configurar então como uma importante tentativa de reformulação e transformação do modelo engessado de ensino numa trajetória onde o próprio discente tem a possibilidade de escolha de seus componentes curriculares.

Por outro lado, reconhece-se que há uma predominância de estudantes que atribuem o interesse pelo BI como uma alternativa para entrada no curso de medicina. Os motivos que os levaram a escolher o BI para ter acesso ao curso de Medicina variaram desde ser uma seleção menos concorrida quanto uma indecisão vocacional. A família e a expectativa de ascensão econômica e social se mostraram como fatores importantes na escolha do cur- 
so. No entanto, o caráter interdisciplinar do BI contribui para que os estudantes possam amadurecer e confirmar a escolha por medicina.

Ainda não existem estudos científicos que demonstrem impactos da formação inicial em Bacharel em Saúde (enquanto primeiro ciclo) na formação médica, no entanto, há de se destacar que a epistemologia que norteia a arquitetura interdisciplinar do BI em saúde visa influenciar na modificação do perfil intelectual dos egressos da educação universitária, como foi apontado por alguns estudantes. Assim, mesmo sendo notável a intenção de cursar medicina como um dos motivos para ingresso no BI saúde, a formação interdisciplinar possibilitada no primeiro ciclo pode contribuir para mudanças no perfil do egresso em medicina no que tange à concepção ampliada de saúde e novos modelos de cuidado à saúde.

\section{Referências}

Almeida-Filho, N. (2007). Universidade Nova: Textos críticos e esperançosos. Brasília, DF: Editora Universidade de Brasília.

Almeida-Filho, N, Mesquita, F, Marinho, M, Lopes, A.A., Lins, E., Ribeiro, N., Macedo, J. Pimentel, A., \& Rego, F. (2010). Memorial da Universidade Nova (2002- 2010). Salvador: Autores. Obra completa no site Scribd. Recuperado de $\leq$ https://pt.scribd.com/document/50945357/Memorialda-Universidade-Nova-2002-2010>

Almeida-Filho, N., Santana, L. A. A., Santos, V. P., Coutinho, D., \& Loureiro, S. (2014). Formação médica na UFSB: I. Bacharelado interdisciplinar em saúde no primeiro ciclo. Revista Brasileira de Educação Médica, 38(3), 337-348. Recuperado de https://dx.doi.org/10.1590/SO100$\underline{55022014000300008}$

Almeida, M. E. G. G. \& Magalhães, A. S. (2011). Escolha profissional na contemporaneidade: projeto individual e projeto familiar. Rev. Bras. Orientac. Prof., 12(2), 205-2 14. Recuperado de http://pepsic. bvsalud.org/scielo.php?script=sci issues\&pid=1679-3390\&lng $=$ pt\&nrm=iso

Almeida, M. E. G. G. \& Pinho, L. V. (2008). Adolescência, família e escolhas: implicações na orientação profissional. Psicologia Clínica (Rio de Janeiro), 20(2), 173-184. DOI: http://dx.doi.org/10.1590/ So103-56652008000200013

Andrade, J. B. (2014). A evasão nos Bacharelados Interdisciplinares da UFBA: um estudo de caso. (2014). Dissertação de Mestrado, Programa de Pós-graduação em Estudos Interdisciplinares sobre a Universidade, Universidade Federal da Bahia, Salvador: UFBA.

Bastos, J. C. (2005). Efetivação de escolhas profissionais de jovens oriundos do ensino público: um olhar sobre suas trajetórias. Rev. Bras. Orientac. Prof., 6(2), 31-43.

Bock, A. M. B., Furtado O., \& Teixeira, M. L. T. (2001). Psicologias: uma introdução ao estudo de psicologia. São Paulo: Saraiva.

Carvalho, M. (2009). Influência de pais nas escolhas de carreira dos filhos: visão de diferentes atores. Rev. Bras. Orientac. Prof., 10(2), 33-41.

Costa, J. M. (2007). Orientação profissional: um outro olhar. Psicologia USP, 18(4), 79-87.

Dias, M. S. L \& Soares, D. H. P. (2012). A escolha profissional no direcionamento da carreira dos universitários. Psicologia: Ciência e Profissão (Brasília), 32(2), 272-283. DOI: http://dx.doi. org/10.1590/S1414-98932012000200002

Faria, L. C. (2013). Influência da condição de emprego/desemprego dos pais na exploração e indecisão vocacional de adolescentes. Psicologia: reflexão e crítica (Porto Alegre), 26(4), 772-779. DOI: http:// dx.doi.org/10.1590/So 102-79722013000400018 
Gabel, C. L. M \& Soares, D. H. P. (2006). Contribuições da terapia familiar sistêmica para a escolha profissional. Rev. Bras. Orientac. Prof. (São Paulo), 7(1), 57-64.

IBGE [Instituto Brasileiro de Geografia e Estatística]. (2012). Síntese de indicadores sociais: uma análise das condições de vida da população brasileira 2012. Brasília, DF: Autor.

IHAC [Instituto de Humanidades, Artes e Ciências Professor Milton Santos]. 2017. Quadro de oferta x ocupação de vagas no Ensino de Graduação do IHAC/UFBA. Salvador: Autor.

Kipnis, B. (2000). A pesquisa institucional e a educação superior brasileira: um estudo de caso longitudinal da evasão. Linhas Críticas, 6(11), 109-139.

Lei n. 10.172, de 9 de janeiro de 2001. (2001). Plano Nacional de Educação. Aprova o Plano Nacional de Educação para o decênio de 2001 a 2010 e dá outras providências. Brasília, DF: Presidência da República.

Louzada, R. C. R \& Silva, J. F.(2004). Tornar-se pesquisador: a escolha profissional como um processo. Psicologia em Estudo (Campinas), 9(2), 271-278. DOI: http://dx.doi.org/10.1590/S141373722008000400013

Lucchiari, D. H. \& Bonneaud, A. L. (2006). Le genoprofessiogramme et le choix de la profession. Rev. Bras. Orientac. Prof. (São Paulo), 7(1), 57-64.

Luna, I. N. (2012). Empreendedorismo e orientação profissional no contexto das transformações do mundo do trabalho. Rev. Bras. Orientac. Prof. (São Paulo), 13(1), 111-116.

Macedo, R. (1998). Seu diploma, sua prancha: como escolher a profissão e surfar no mercado de trabalho. São Paulo: Saraiva.

Magalhães, M., Straliotto, M., Keller, M., \& Gomes, W. B. (2001). Eu quero ajudar as pessoas: a escolha vocacional da psicologia. Psicologia: Ciência e Profissão (Brasília, DF), 21(2), 10-27. DOI: http:// dx.doi.org/10.1590/S1414-98932001000200003

Mazoni, I., Custório, L., \& Sampaio, S. M. O. (2011). O Bacharelado Interdisciplinar da Universidade Federal da Bahia. O que dizem os estudantes? In S. M. R. Sampaio (Org.), Observatório da vida estudantil: primeiros estudos (pp. 229-248). Salvador: EDUFBA.

Melsert, A. L. M. \& Bicalho, P. P. G. (2012). Desencontros entre uma prática crítica em psicologia e concepções tradicionais em educação. Psicologia Escolar e Educacional (Maringá), 16(1), 153-160.

Minayo, M. C. S. (2008). O desafio do conhecimento (11a ed.) São Paulo: Hucitec.

Moreira, F. C. S. (2000). Orientação profissional: uma visão multidisciplinar. In M. D. Lisboa \& D. H. P. Soares (Orgs.), Orientação profissional em ação: formação e prática de orientadores (pp. 134-143). São Paulo: Summus.

Natividade, M. R. \& Brasil, V. (2006). A escolha profissional entre os bombeiros militares. Rev. Bras. Orientac. Prof. (São Paulo), 7(1), 37-43.

Neiva, K. M. C. (2007). Processos de escolha e orientação profissional. São Paulo: Vetor.

Oliveira, C. M. R. \& Neiva, K. M. C. (2013). Orientação vocacional/profissional: avaliação de um projeto piloto para estudantes da educação profissional. Rev. Bras. Orientac. Prof., 14(1), 133-143.

Oliveira, C. T. \& Dias, A. C. G. (2013). Percepções parentais sobre sua participação no desenvolvimento profissional dos filhos universitários. Rev. Bras. Orientac. Prof., 14(1), 61-72.

Pereira, F. N. \& Garcia, A. (2007). Amizade e escolha profissional: influência ou cooperação? Rev. Bras. Orientac. Prof., 8(1), 71-86. 
Pimentel, A., Rubim, A. A., Bastos, A. V., Embiruçu, M., Marinho, M., Nery, M., Pontes, M., \& Almeida-Filho, N. Projeto pedagógico dos Bacharelados Interdisciplinares. 2008. Recuperado de https://www.ufba.br/sites/portal.ufba.br/files/implant_reuni.pdf

Phillips, N. \& Hardy, C. (2002). Discourse analysis. Investigating processes of social construction. Thousand Oaks, CA: Sage Publications.

Ribeiro, M. M. F., Leal, S. S., Diamantino, F. C., Bianchi, H. A. (2011). A opção pela medicina e os planos em relação ao futuro profissional de estudantes de uma faculdade pública brasileira. Revista Brasileira de Educação Médica, Belo Horizonte, 35(3), 405-411.

Sampaio, S. M. R, Barbosa, J. S., Santos, I. D, Fernandes, N., \& Dantas, M. (2013). Nova universidade, novos estudantes: quem são e o que esperam os estudantes dos Bacharelados Interdisciplinares da Universidade Federal da Bahia. In G. Santos \& S. M. R. Sampaio (Orgs.), Observatório da vida estudantil: universidade, responsabilidade social e juventude (pp. 239-254). Salvador: EDUFBA.

Santos, P. J. (2010). Família e indecisão vocacional: revisão da literatura numa perspectiva da análise sistêmica. Rev. Bras. Orientac. Prof., 11(1), 83-94.

Silva, R. L. L, Montejunas, P. R., Hipólito, O., \& Lobo, M. B. C. M. (2007). A evasão no ensino superior brasileiro. Cadernos de Pesquisa, 37(132), 641-659.

Teixeira, A. M. F. (2011). Entre a escola pública e a universidade: longa travessia para jovens de origem popular. In S. M. R. Sampaio (Org.), Observatório da vida estudantil: primeiros estudos (pp. 67-91). Salvador: EDUFBA.

Teixeira, C., Coelho, M. T., \& Rocha, M. N. D. (2014). Bacharelado interdisciplinar: uma proposta inovadora na educação superior em saúde no Brasil. Ciência e Saúde Coletiva, 18(6), 1635-1646. DOI: https://dx.doi.org/10.1590/S1413-81232013000600015

Torres, M. L. C. (1998). O processo clínico de orientação profissional. Rev. Bras. Orientac. Prof., 2(2), 29-37.

Traverso-Yépez, M. (2008). A psicologia social e o trabalho em saúde. Natal: EDUFRN.

Veras, R. M. (2011). Etnografia Institucional: conceito, usos e potencialidades em pesquisas no campo da saúde. Saúde E̊ Transformação Social, 2, 1, 58-66.

Veras, R. M., Lemos, D.V.S., \& Macedo, B.T. F. (2015). A trajetória da criação dos bacharelados interdisciplinares na Universidade Federal da Bahia. Avaliação, Campinas, 20(3), 62 1-641.

Willig, C. (2010). Introducing qualitative research in psychology. Adventures in theory and method. Buckingham, UK: Open University Press. 


\section{RENATA MEIRA VERAS \\ http://orcid.org/0000-0002-1681-1401}

Psicóloga e fisioterapeuta. Doutora em Psicologia Social pela UFRN. Professora associada do Bacharelado Interdisciplinar em Saúde da Universidade Federal da Bahia. Docente permanente do Programa de Pósgraduação Estudos Interdisciplinares sobre a Universidade (PPGEISUUFBA). Bolsista de Produtividade Nível 2 do CNPq.

Endereço institucional: Programa de Pós-Graduação em Estudos Interdisciplinares Sobre a Universidade. UFBA. Rua Barão de Geremoabo, s/n - Ondina - IHAC/UFBA - CEP: 40.170-115 - Salvador/Bahia, Brasil.

E-mail: renata.veras@ufba.br

\section{CAROLINNE MONTES BAPTISTA}

\section{https://orcid.org/0000-0002-5667-8895}

Graduada em Psicologia pela PUC-RS. Pós-Graduada em Neuropsicologia com enfoque Educacional pela FACINTER. Mestre em Estudos Interdisciplinares sobre a Universidade pela UFBA. A tua como psicoterapeuta na Clínica Higéia Saúde Integral.

E-mail: carobap@gmail.com

Submissão em: 06/12/2017

Aceite em: 14/10/2018

Financiamento: Fundação de Amparo à Pesquisa do Estado da Bahia - FAPESB. Bolsa de Mestrado.

Consentimento de uso de imagem: Não se aplica. 